\title{
Three new species of Sternaspidae (Annelida: Sedentaria) from Thailand
}

\author{
JINTANA PLATHONG ${ }^{1,2}$, SAKANAN PLATHONG ${ }^{2 *} \&$ SERGIO I. SALAZAR-VALLEJO ${ }^{3}$ \\ ${ }^{1}$ Marine Ecosearch Management Co., Ltd., 4/31 Moo 1, Namnoi, Hat Yai, Songkhla, 90110, Thailand. \\ ”klaklong@hotmail.com; @ https://orcid.org/0000-0002-2136-3770 \\ ${ }^{2}$ Marine Science Learning Center, Faculty of Science, Prince of Songkla University, Hat Yai, Songkhla, 90112, Thailand. \\ "="sakanan2004@yahoo.com; 이ttps://orcid.org/0000-0003-3473-1680 \\ ${ }^{3}$ Depto. Sistemática y Ecología Acuática, El Colegio de la Frontera Sur, Chetumal, Quintana Roo, México.

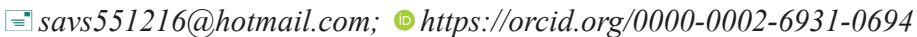 \\ ${ }^{*}$ Corresponding author
}

\begin{abstract}
In this contribution, three new species of sternaspids collected from sediments along the coast of southern Thailand are described: Petersenaspis apinyae sp. nov. from a depth of 50-80 m offshore in the Gulf of Thailand; P. narisarae sp. nov. from $9 \mathrm{~m}$ depth in the Songkhla Sea, Gulf of Thailand; and P. pakbaraensis sp. nov. from tidal mudflats on the Andaman Coast. All three species resemble P. palpallatoci Sendall \& Salazar-Vallejo, 2013. They differ mainly in the pigmentation and shape of the shield, the number of ventral chaetae and chaetae at the posterior shield, body papillae, and size of the abdomen. Further, $P$. apinyae sp. nov. is clearly distinguished from other species of the genus by having dark orange to red butterfly wing-shaped shields, with strongly curved anterior margins. P. narisarae sp. nov. differs from other species by having concentric colored bands over shields and an expanded oval abdomen. P. pakbaraensis sp. nov. can be distinguished from other species by its dark brown-purple shield and laterally expanded fan. These three species have a unique character in their branchial plates: long brownish filaments. A key to the identification of all species of Petersenaspis is included.
\end{abstract}

Key words: Mu Ko Phetra National Park, Songkhla Sea, Petersenaspis, sternaspids, taxonomy

\section{Introduction}

Sternaspidae are still poorly known in Thailand and it is not known how many species of Sternaspidae there are in the country. Only one species has been described, Sternaspis andamanensis Sendall \& Salazar-Vallejo, 2013, from Phuket, in the Andaman Sea (Sendall \& Salazar-Vallejo 2013). Two sternaspid species, Petersenaspis sp. and $S$. andamanensis, were reported by Tantikamton et al. (2015) from mudflats in Pak Bara, Satun Province, on the southern Andaman coast of Thailand. Rodcharoen (2009) studied the macrobenthos from the inshore island of Ko Nu, in the Gulf of Thailand off Songkhla Province, and reported S. scutata Ranzani, 1817, a species formerly regarded as cosmopolitan. In our earlier studies covering different regions of Thailand (Plathong et al. 2014), we identified the collected sternaspids as $S$. andamanensis, S. fossor, S. scutata and Petersenaspis cf. palpallatoci. Most previous research reported only S. andamanensis, S. scutata and S. affinis Stimson, 1864 (Angsupanich \& Kuwabara 1995; Rodcharoen 2009). In our previous study, we followed the older names of S. scutata and S. fossor. However, after the revision of Sternaspidae (Sendall \& Salazar-Vallejo 2013), we reviewed the specimens in our collections from many areas of Thailand and found that they had different types of shields. We are now preparing a series of contributions in the group. The first paper deals with the genus Petersenaspis Sendall \& Salazar-Vallejo, 2013, and we will continue with the genus Sternaspis Otto, 1820 in a subsequent paper. In this study, we describe three new species of the genus Petersenaspis Sendall \& Salazar-Vallejo, 2013 which can be easily recognized from their shields and branchial shapes.

To date, there are five validated species of Petersenaspis Sendall \& Salazar-Vallejo, 2013 (Read \& Fauchald 2021) and we erect three new species described here. The eight species are: P. capillata Nonato 1966; P. deani 
Salazar-Vallejo, 2017; P. harrisae Salazar-Vallejo, 2017; P. palpallatoci Sendall \& Salazar-Vallejo, 2013; P. salazari Wu \& Xu, 2017; P. apinyae sp. nov.; P. narisarae sp. nov. and P. pakbaraensis sp. nov. (Fig. 1). Among these eight species, only four have shields with both a median notch and two lateral notches. The four are P. palpallatoci Sendall \& Salazar-Vallejo, 2013 and the three new species from Thailand described herein.

\section{Material and methods}

Samples were collected from three sites during different projects. The first site was an offshore area in the Gulf of Thailand, during a project called "Long-term environmental monitoring at the offshore Petroleum Production Area in the Gulf of Thailand" was conducted from 2009-2019. The project assessed benthic diversity at several stations in offshore petroleum concession areas. The second site was in the Songkhla Sea, in the Gulf of Thailand where the four-year project "Marine and Coastal Resources Databases and Marine Community under Petroleum Platform in Songkhla Province" was completed in 2016. The project investigated the seasonal variation of benthic fauna in Songkhla Province. The third site was in the intertidal zone of Pak Bara, Mu Ko Phetra National Park, off the Andaman Coast of Southern Thailand. The project was conducted from 2018 to 2020 by the Department of National Parks, Wildlife and Plant Conservation. Specimens of Sternaspidae were collected from sediment taken from these three areas.

Specimens were collected with different equipment. The methods used in each of the three areas were as follows. In the offshore Petroleum Production Area in the Gulf of Thailand $\left(8^{\circ} 22^{\prime} 53^{\prime \prime}-10^{\circ} 46^{\prime} 59^{\prime \prime} \mathrm{N}, 100^{\circ} 48^{\prime} 03^{\prime \prime}-\right.$ $\left.102^{\circ} 05^{\prime} 25^{\prime \prime} \mathrm{E}\right)$, a Van Veen grab $\left(0.04 \mathrm{~m}^{2}\right)$ was used at depths ranging from 50 to $80 \mathrm{~m}$. In the Songkhla Sea, in the southern Gulf of Thailand $\left(7^{\circ} 14^{\prime} 21^{\prime \prime}-7^{\circ} 49^{\prime} 22^{\prime \prime} \mathrm{N}, 100^{\circ} 24^{\prime} 42^{\prime \prime}-100^{\circ} 49^{\prime} 01^{\prime \prime} \mathrm{E}\right)$, a Van Veen grab $\left(0.1 \mathrm{~m}^{2}\right)$ was used at depths ranging from 9 to $27 \mathrm{~m}$. In the intertidal zone of Pak Bara, Mu Ko Phetra National Park (6 $6^{\circ} 1^{\prime} 07^{\prime \prime}-6^{\circ} 51^{\prime} 14^{\prime \prime} \mathrm{N}$, 99 43 '23" $-99^{\circ} 43^{\prime} 38^{\prime \prime}$ ), specimens were collected by quadrate sampling at low tide (Fig. 2). The collected samples were sieved in the field with $2.0 \mathrm{~mm}, 1.0 \mathrm{~mm}$ and $0.5 \mathrm{~mm}$ mesh screens. Later, water and sediment from the sieved grab samples were passed through a $300 \mu \mathrm{m}$ filter bag. Specimens retained by both separation methods were separately fixed with a solution of $4 \%$ formaldehyde in seawater. In the laboratory, samples were washed with freshwater and transferred to $70 \%$ ethanol.

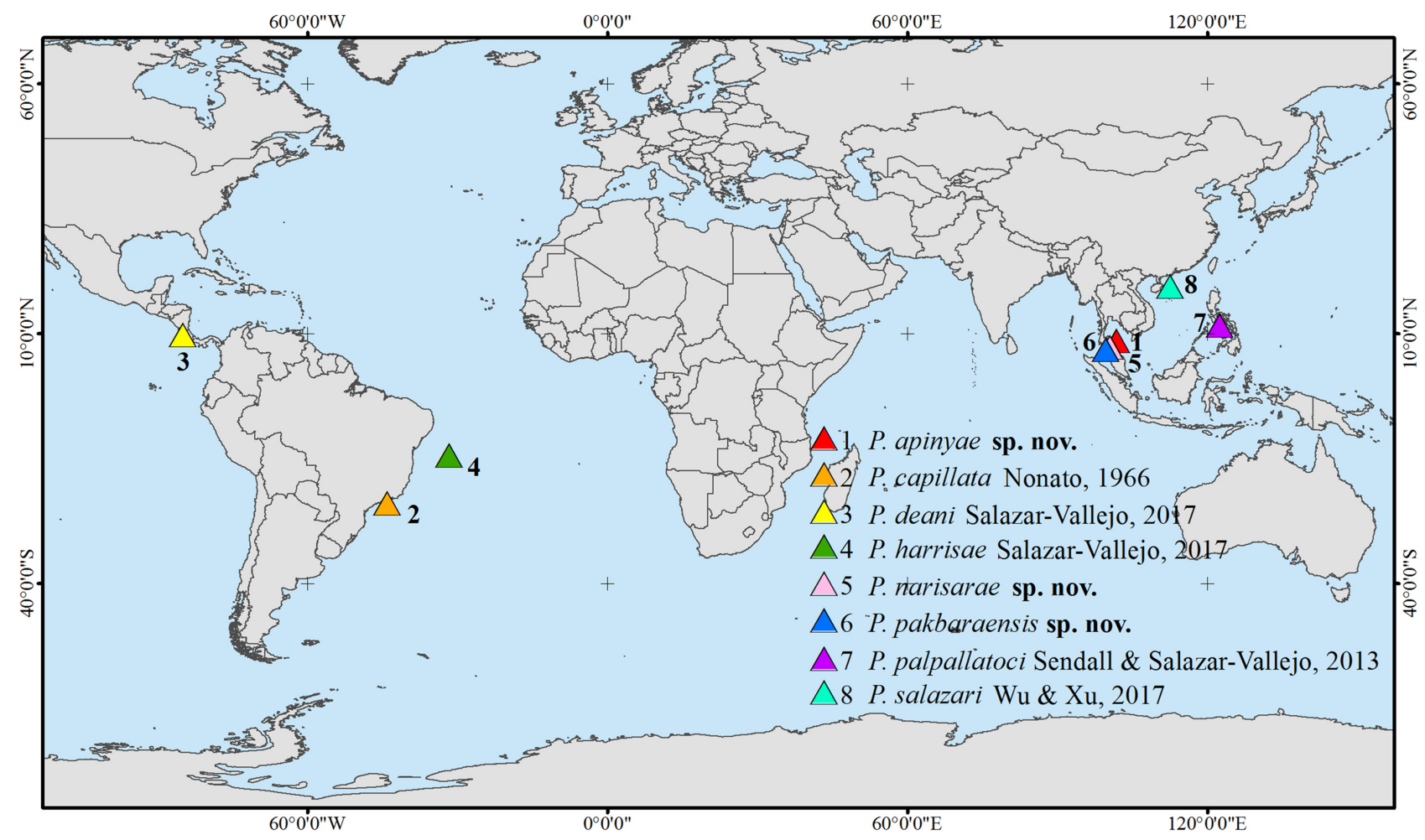

FIGURE 1. Type localities of the accepted species of Petersenaspis Sendall \& Salazar-Vallejo, 2013. 


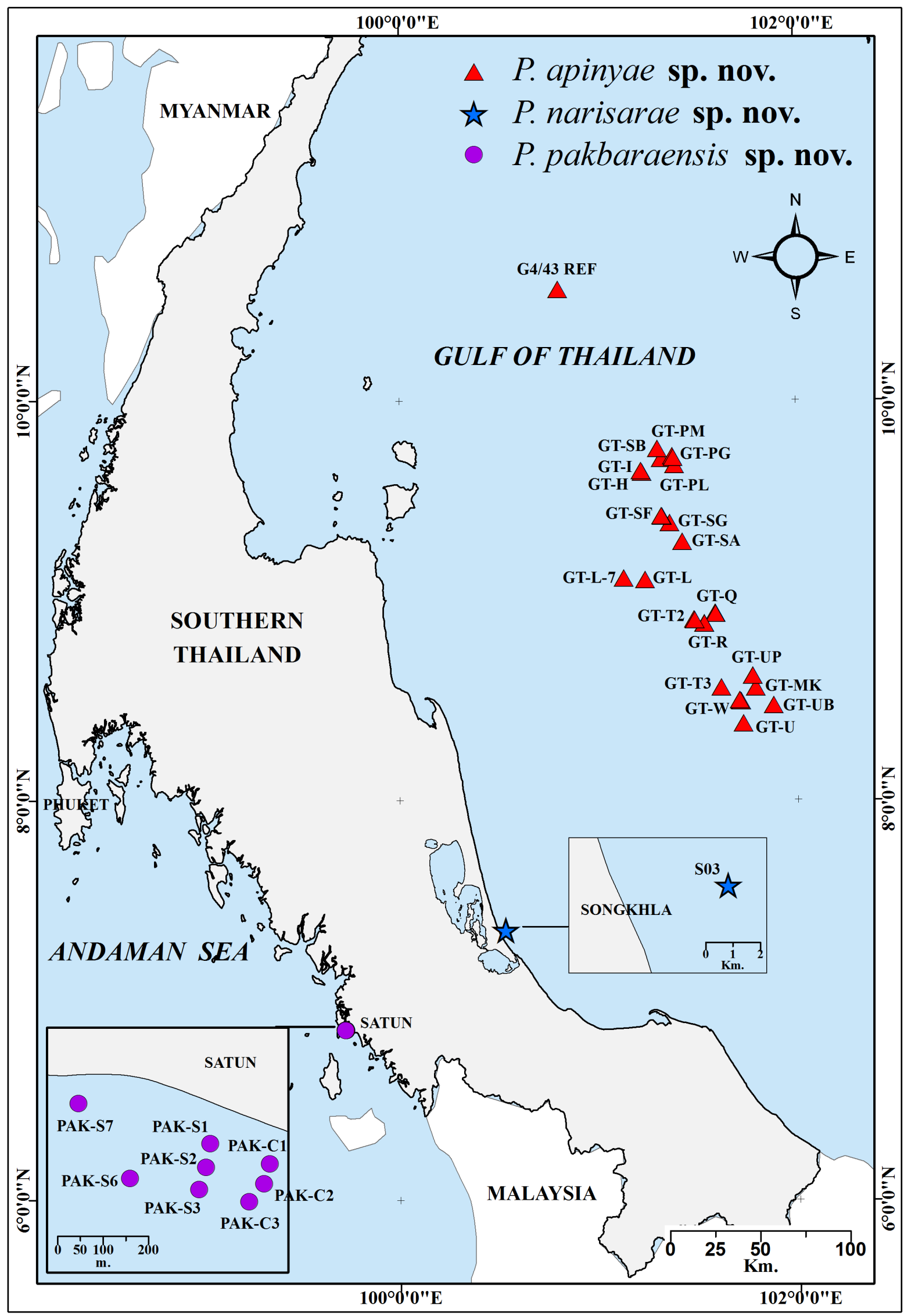

FIGURE 2. Sampling sites in the Gulf of Thailand and Andaman Sea where specimens of $P$. apinyae sp. nov. (triangles), $P$. narisarae sp. nov. (stars), and P. pakbaraensis sp. nov. (circles) were collected. 
Polychaetes were sorted into taxonomic groups using a stereo microscope, and those thought to belong to new species were examined under stereo light microscopes. Light photographs and measurements of the specimens were produced using a stereo microscope (Olympus SZX16) with a digital camera (DP74). Stacks of multifocal shots were merged into a single photograph using the Helicon Focus program. Scanning electron microscope (SEM) images were produced with a JEOL JSM-5800LV microscope, and a field emission scanning electron microscope (Apreo, FEI). Specimens were critical-point dried, mounted on stubs and coated with gold. Type specimens were deposited at the Princess Maha Chakri Sirindhorn Natural History Museum, Prince of Songkla University (PSUZC), Thailand, and at the Australian Museum (AM), Sydney, Australia. Additional material is maintained in the personal collections of JP and SP at MEM.

Morphological measurements and taxonomic descriptions based on the holotypes, and information about variability found in the paratypes. The confirmation of the taxonomic status of the new species was based on a comparison of the diagnostic characters of all recognized species of Petersenaspis Sendall \& Salazar-Vallejo, 2013 as described by Sendall \& Salazar-Vallejo (2013), Salazar-Vallejo (2017) and Wu \& Xu (2017). A table of the main diagnostic characters of the new species and closely related species has been appended to this paper. In the key to species below, the size of genital papillae was incorporated after a comparison of specimens of similar size collected during the same season, such that they are regarded as long if their size is equivalent to the length of one adjacent segment, or short if barely visible. For example, for P. palpallatoci Sendall \& Salazar-Vallejo, 2013, the holotype, collected in July, was $11 \mathrm{~mm}$ long, and its genital papillae are long. P. pakbaraensis sp. nov., although only $6 \mathrm{~mm}$ long, also has long genital papillae. On the contrary, in P. apinyae sp. nov. and P. narisarae sp. nov., the genital papillae are minute, and barely visible. The relative size might depend on the sexual maturity of the specimens, and this explains why this feature was considered in combination with others.

\section{Systematics}

\section{Family Sternaspidae Carus, 1863}

\section{Genus Petersenaspis Sendall \& Salazar-Vallejo, 2013}

Diagnosis (after Fiege 2019). Sternaspids with introvert hooks subdistally expanded. Preshield region with eight segments. Ventrocaudal shield stiff with poorly developed ribs and no concentric lines.

\section{Petersenaspis apinyae sp. nov.}

LSID urn:lsid:zoobank.org:act:5083A547-AD34-4A1E-8328-1B49765744F8

Figs $3-4$

Material examined. 43 specimens, all collected from 50-80 m deep in the offshore Petroleum Production Area, the Gulf of Thailand, Western Pacific; mud mixed with sand and shells; coll. Marine Ecosearch Management Company

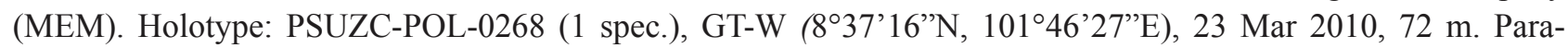

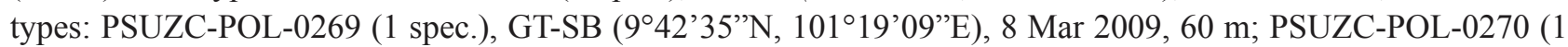

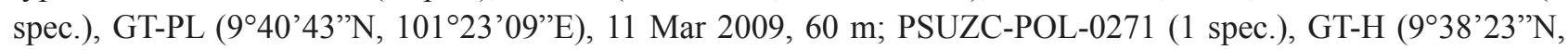
101 ${ }^{\circ} 13$ '21”E), 14 Mar 2009, 60 m; PSUZC-POL-0272 (1 spec.), GT-MK (8³3’48”N, 10147’22”E), 20 Mar 2009, 80 m; PSUZC-POL-0273 ( 1 spec. on SEM stub), GT-U ( $8^{\circ} 23^{\prime} 02^{\prime \prime} N$, 101 ${ }^{\circ} 43^{\prime} 39^{\prime \prime}$ E), 21 Mar 2009, 80 m; PSUZCPOL-0274 (1 spec.), GT-R ( $8^{\circ} 53^{\prime} 01^{\prime \prime N}$, 101³1'56”E), 20 Mar 2010, 70 m; PSUZC-POL-0275 (1 spec.), GT-T2-2

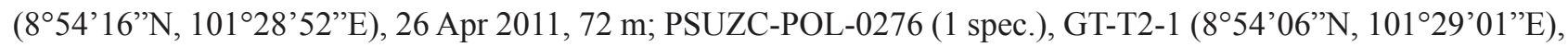
27 Apr 2011, 72 m; PSUZC-POL-0277 (1 spec.), GT-T3 (8³3’52”N, 101³7’02”E), 28 Apr 2011, 72 m; PSUZCPOL-0278 (2 specs., 1 juvenile), GT-UP ( $\left.8^{\circ} 37^{\prime} 16^{\prime \prime} \mathrm{N}, 101^{\circ} 46^{\prime} 27^{\prime \prime} \mathrm{E}\right), 1$ Apr 2012, 76 m; PSUZC-POL-0279 (1 spec.), GT-L (9॰06'15”N, 101¹4'05”E), 10 Jun 2015, 50 m; PSUZC-POL-0280 (1 spec.), GT-SG (9²3'13”N, 101²1'35”E), 12 Jun 2015, 50 m; PSUZC-POL-0281 (1 spec.), GT-SF (9॰25’09”N, 101¹9'18”E), 11 Jun 2015, 50 m; PSUZC-POL-0282 (1 spec.), GT-SA (9¹7’37’'N, 101²5'27’'E), 12 Jun 2015, 50 m; PSUZC-POL-0283 (1 spec., on SEM stub), GT-L-7 (9॰06’43”N, 10107’40”E), 9 Sep 2015, 64 m; PSUZC-POL-0284 (1 spec.), GT-W2-19 


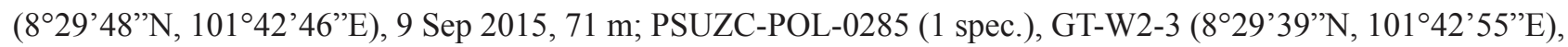
9 Sep 2015, 71 m; PSUZC-POL-0286 (1 spec.), GT-W2-11 (8³0’02”N, 101²’32”E) 10 Sep 2015, 71 m; PSUZCPOL-0287 (1 spec.), GT-R ( $8^{\circ} 53^{\prime} 04^{\prime \prime} \mathrm{N}, 101^{\circ} 31^{\prime} 59^{\prime}$ 'E), 25 Jun 2016, 69 m; PSUZC-POL-0288 (1 spec., on SEM stub), GT-SF $\left(9^{\circ} 25^{\prime} 18^{\prime \prime N}, 101^{\circ} 19^{\prime} 09^{\prime}\right.$ 'E), 22 Jun 2018, 69 m; PSUZC-POL-0289 (1 spec., juvenile), GT-PG-23

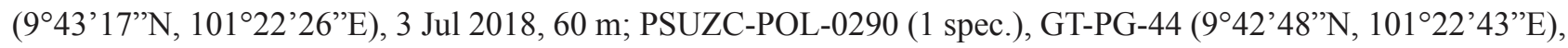
5 Jul 2018, 60 m; AM W.52923 (1 spec.), G4/43 REF (10³3’26”N, 10048’03”E), 15 Apr 2011, 60 m.

Additional material: The offshore Petroleum Production Area, the Gulf of Thailand: 2 specs., GT-T2-3

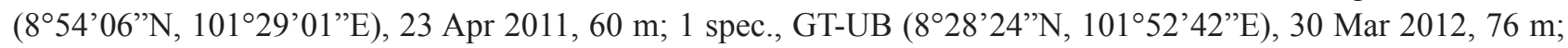

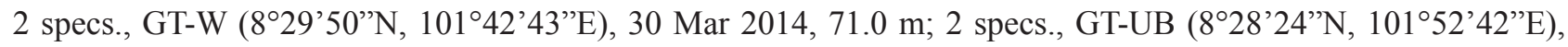
9 Sep 2015, 70 m; 1 spec., GT-I (9³8'54”N, 101¹2’55”E), 11 Sep 2015, 68 m; 1 spec., GT-PM-23 (945’28”N, 101¹7'59”'E), 3 Jul 2018, 73 m; 1 spec., GT-R (853’02”N, 101³1’56”E), 28 Mar 2019, 70 m; 4 specs., GT-Q,

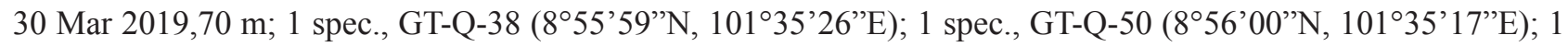

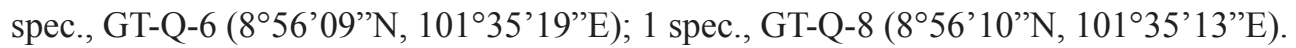

Type locality. Gulf of Thailand, offshore petroleum concession area (Fig. 2).

Description. Holotype complete without sediment particles; body $9.2 \mathrm{~mm}$ long, $3.7 \mathrm{~mm}$ wide, abdomen 7.0 $\mathrm{mm}$ long, about 20 segments, whitish in alcohol (Fig. 3A-B). Abdominal papillae thin, long. Paratypes, 13 specimens complete with exposed anterior region: 11 specimens mature, body 4.0-12.6 mm long, 1.8-3.5 mm wide, abdomen 2.7-4.2 mm long, about 20 segments: 2 specimens juvenile, body $2.0-2.3 \mathrm{~mm}$ long, $0.8 \mathrm{~mm}$ wide, abdomen $1.5-1.6 \mathrm{~mm}$ long. Eight specimens with introvert invaginated; body $5.4-8.3 \mathrm{~mm} \mathrm{long}, 2.7-4.2 \mathrm{~mm}$ wide, and abdomen 5.2-6.7 mm long.

Prostomium rounded (not completely exposed in holotype but fully exposed in some paratypes); peristomium rounded, with short papillae extended behind prostomium. Mouth circular with papillae extending from base of prostomium to anterior edge of first chaetiger (Figs 3C, 4A-B).

First three chaetigers with 11-16 large golden spatulate hooks and small golden spatulate hooks with up to 11 hooks, without subdistal dark areas (Figs 3A-C, 4A-D). Genital papillae short, conical, protrude ventrally from body wall between segments 7 and 8 (Figs 3A-B, 4A-D).

Pre-shield region of eight segments (Fig. 3A-B), with single lateral bundles of 2-4 (mostly 3) short thin capillary chaetae (Fig. 4E) protruding from body wall along segments 8-14. Paratype with capillaries along chaetigers 8-15. Body papillae along dorsal and ventral surfaces small, minute; lateral papillae long, thin (Fig. 4F-G).

Ventro-caudal shield with sediment particles and abundant, fine, long papillae; shield wider than long, butterfly wing-shaped, orange to reddish, integument without ciliary clumps; suture extended throughout shield. Shield without well-developed ribs and concentric lines. Anterior margins angular, anterior depression shallow. Anterior keels exposed. Lateral margins strongly curved, expanded anteriorly, reduced medially to posterior. Posterior shield wide and slightly curved. Fan with a median notch and two lateral notches. Median notch shallow (Figs 3A, E-J, 4D, G-H). Juvenile ventro-caudal shield yellowish with anterior and lateral margins rounded, fan with a median notch and smooth margin. Peg chaetae absent.

Chaetal fascicles on marginal shield include 10 lateral fascicles, chaetae of each fascicle in offset and parallel arrangement, no concentric lines, and 12 posterior fascicles, 7 with 3-4 chaetae each (1-2 fine capillary chaetae) and 5 in lateral notch with about 3 delicate and very long capillary chaetae. The long fine chaetae are located at both sides of the lateral notch, near lateral chaetae, longer than abdomen region, or about 3 times as long as posterior chaetae. These chaetae are fragile, some broken in every specimen, about 3-5 intact chaetae instead of 15 .

Branchial filaments abundant (Figs 3A-B, E, 4F, H), consisting of two parts; the first part is the branchial body, coiled, the second a long filament with bloated posterior (Figs 3A-B, 4H, F, I), the base of branchial body connected to branchial plate. Branchial plates with long papillae and sediment particles (Fig. 3D). The anterior branchial body can retract leaving the long filament exposed. The branchia and filament are connected by a small ring (Fig. 4K). Branchiae are whitish, neither smooth nor covered with cilia (Fig. 4L), and the filament holder is golden or brownish, smoother than the branchia and composed of small rings (Fig. 4M), the posterior end is bloated with larger rings. The outer surface of each posterior ring is embossed with a row of ovoid shapes and tips roughly resembling the pads of a gecko's feet. Their tips are often swollen and have a tapered end (Fig. 4J). They might possibly help by sucking or sticking to adjacent sediment particles to support the body.

Variation. Juveniles with body wall and ventro-caudal shield very thin, transparent; shield light yellow to light brown. Adults with thicker body wall and harder shields. 

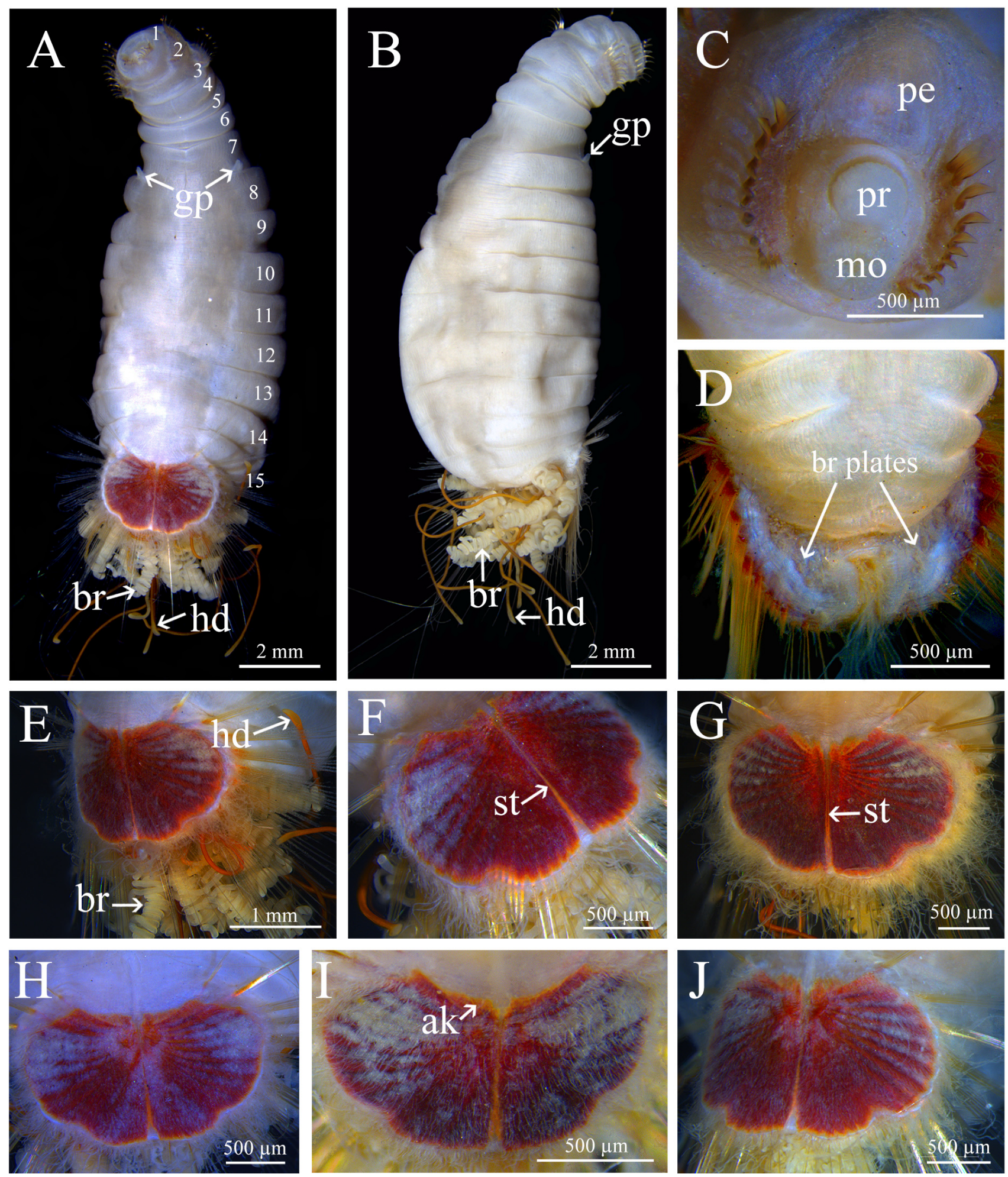

FIGURE 3. Petersenaspis apinyae sp. nov. Light photographs (A, B, E. Holotype PSUZC-POL-0268; C, F. PSUZC-POL0276; D. PSUZC-POL-0277; G. PSUZC-POL-0284; H. PSUZC-POL-0274; I. PSUZC-POL-0281; J. PSUZC-POL-0286). A. Complete specimen, dorsal view; B. Same, lateral view; C. Prostomium, frontal view; D. Branchial plate after removal of branchial and interbranchial filaments, ventral view; E-F. Ventro-caudal shield, oblique lateral view; G-J. Same, frontal view. Abbreviations: number of segments 1-15, anterior keel ak, branchial filament br, genital papilla gp, straight filament hd, mouth mo, peristomium pe, prostomium pr, suture st. 

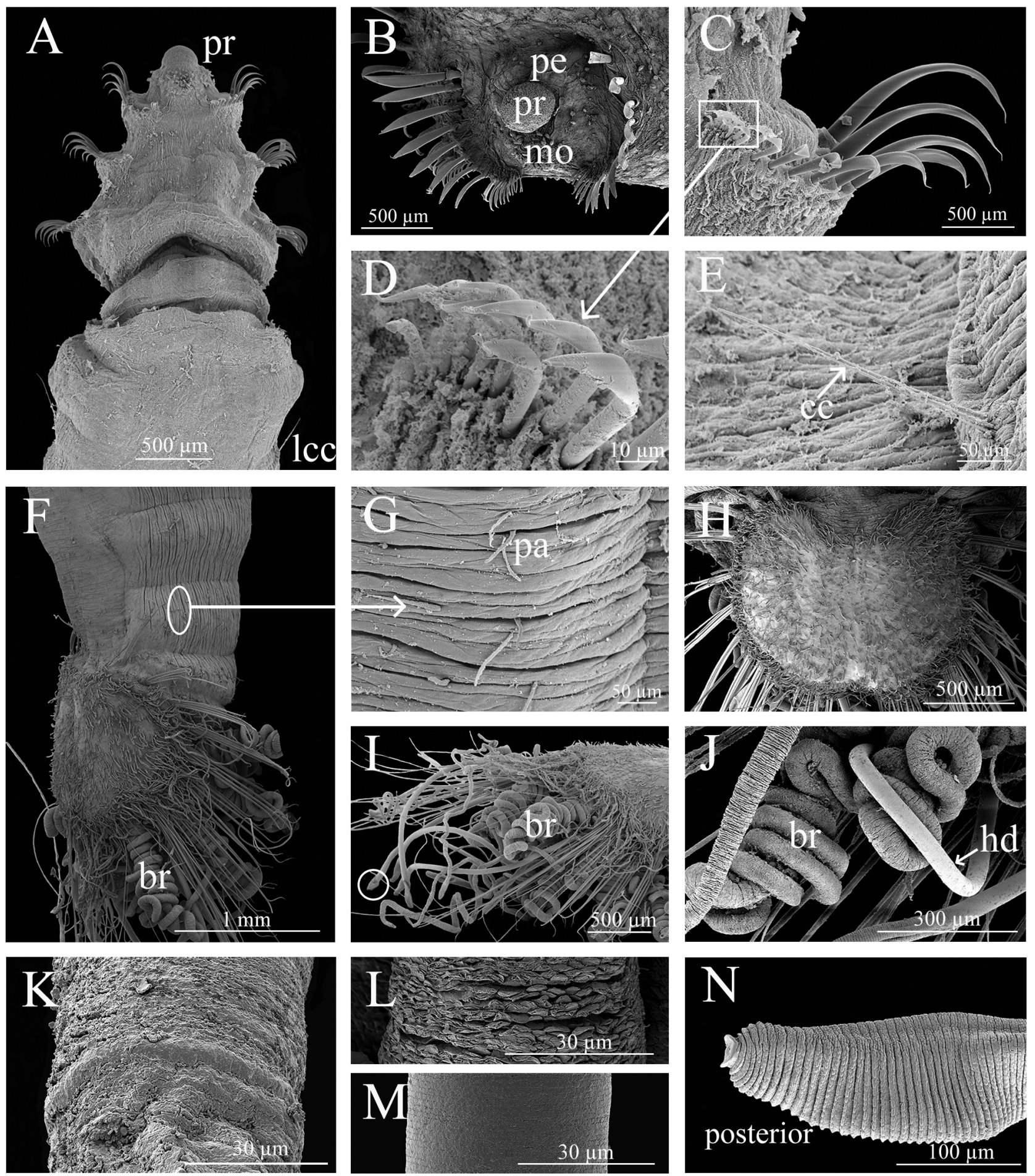

FIGURE 4. Petersenaspis apinyae sp. nov. (A, C, D-F, I-K. PSUZC-POL-0273; B, L-N. PSUZC-POL-0283; H. PSUZCPOL-0288). A. Anterior region, ventral view. B. Anterior end, frontal view; C. Spatulate neurohooks, lateral view; D. Close up of smaller chaetae in rectangle of C.; E. Lateral simple chaetae of abdomen arrow points to capillary chaeta, lateral view; F. Posterior region, area in oval with lateral papillae, lateral view; G. Same, close up of oval area of F., lateral body surface; H. Ventrocaudal shields, frontal view; I. Posterior end, elongated papillae of lateral body in circle, lateral view; J. Branchiae and straight filament, lateral view; K. Ring at the connection between branchia and filament, top view; L. Close up texture of branchia, top view; M. Close up, filament surface; N. Close up, tip of posterior filament. Abbreviations: branchial filament br, capillary chaeta cc, straight filament hd, lateral capillary chaeta lcc, mouth mo, papilla pa, peristomium pe, prostomium pr. 
Etymology. The species name is in recognition of Mrs. Apinya Sukolra of the SEM section, Office of Scientific Instrument and Testing (OSIT), Prince of Songkla University, for her assistance with SEM photographs of polychaetes during the last 4 years.

Habitat. Found at 50-80 m depth, in muddy sediments mixed with sand and shells, offshore Gulf of Thailand.

Distribution. Only known in the offshore Petroleum Production Area, Gulf of Thailand (Figs 1, 2).

Remarks. Petersenaspis apinyae sp. nov. resembles P. palpallatoci Sendall \& Salazar-Vallejo, 2013, P. narisarae sp. nov., and $P$. pakbaraensis sp. nov. in having homogenously pigmented shields and both a median notch and two lateral notches. However, P. apinyae sp. nov. has more introvert hooks and posterior chaetae than P. palpallatoci with 20-22 introvert hooks per fascicle and 12 fascicles of posterior shield chaetae. P. palpallatoci has about 12-14 introvert hooks and 10 fascicles of posterior shield chaetae (Sendall \& Salazar-Vallejo 2013). Moreover, $P$. apinyae sp. nov. has a butterfly wing-shaped shield with lateral margins strongly curved and expanding anteriorly; and more lateral abdomen chaetae than P. palpallatoci, with up to 3 simple chaetae per bundle from segment 8-15. In P. palpallatoci, lateral shield margins are rounded, and there are only 2 simple lateral abdominal chaetae per bundle from segment 9-10 (Sendall \& Salazar-Vallejo 2013).

Petersenaspis apinyae sp. nov. differs from P. pakbaraensis sp. nov. by having 20-22 spatulate hooks per fascicle whereas $P$. pakbaraensis sp. nov. has 13-19. P. apinyae sp. nov., unlike $P$. pakbaraensis sp. nov., does not have ciliary clumps, and the median notch is narrower and shallower than in P. pakbaraensis. The posterior shield is wide and slightly curved, whereas the posterior shield of P. pakbaraensis sp. nov. is narrow, protruding and strongly curved.

Petersenaspis apinyae sp. nov. differs from $P$. narisarae sp. nov. by having a homogenously pigmented shield whereas $P$. narisarae has colored bands on its shield. Also, the abdomen of $P$. apinyae sp. nov. is not expanded.

\section{Petersenaspis narisarae sp. nov.}

LSID urn:lsid:zoobank.org:act:9862A44C-9251-43C9-A85C-9827D8E081C0

Fig. 5

Material examined. Seven specimens from the Songkhla Sea, Gulf of Thailand, Western Pacific, from muddy sediments mixed with sand and shells; coll. Marine Ecosearch Management Company (MEM). All specimens were collected from sampling site S03 (7²1'02'N, 100³1'45 ’'E), at 9 m. Holotype: PSUZC-POL-0291 (1 spec.), 21 May 2015. Paratypes: S03, PSUZC-POL-0292 (2 specs., 1 juvenile), 30 Jan 2012; PSUZC-POL-0293 (1 spec., juvenile), 24 May 2012; PSUZC-POL-0294 (1 spec., juvenile), 11 Oct 2012; PSUZC-POL-0295 (1 spec., juvenile), 17 May 2016; AM W.52925 (1 spec.), 1 Oct 2012.

Description. A small species, holotype complete, body whitish without sediment particles; anterior part not exposed, branchiae whitish, coiled, long straight filaments orange brown. Body $5.3 \mathrm{~mm}$ long, $3.5 \mathrm{~mm}$ wide, and abdomen $4.3 \mathrm{~mm}$ long (Fig. 5A-B). Paratypes, two large specimens, introvert invaginated; body 5.2-6.2 mm long, 3.6-4.3 mm wide. Others juvenile, two specimens with anterior region not exposed but with golden chaetae visible through body wall (Fig. 5D), 2.3-2.9 mm long, 1.2-1.7 mm wide, and abdomen 1.8-1.9 mm long; two specimens introvert exposed 1.3-4.3 $\mathrm{mm}$ long, $1.2-1.3 \mathrm{~mm}$ wide, and abdomen $0.7-2.7 \mathrm{~mm}$ long.

Prostomium, peristomium and mouth not exposed, prostomium and middle of body fragile.

First three chaetigers not visible in holotype or paratypes. In small paratypes, golden spatulate hooks visible through body wall (Fig. 5D); one juvenile had introvert exposed showing golden spatulate hooks.

Pre-shield region with eight segments, oval shape (Fig. 5A, C) with single lateral bundles of 2-3 short, thin capillary chaetae, protruding from body wall along segments 9-13 in both holotype and paratypes. Body papillae at the dorsal and ventral surfaces small, minute; lateral body papillae long, thin.

Ventro-caudal shield yellow-orange-reddish, butterfly wing-shaped with three colored bands; outer band yellow-orange, middle band reddish and widest, inner band darker and narrowest. Ventro-caudal shield plate with anterior, lateral and posterior margins rounded, fan with a deep median notch, margins smooth. Few papillae on shield surface and integument, without ciliary clumps. Radial ribs distinct, no concentric lines; posterior shield margin round (Fig. 5A, C, E, F).

Marginal shield chaetae fascicles include 9-10 lateral fascicles in oval arrangement with offset and parallel fascicles, and 12 posterior fascicles, each with 2-3 chaetae: 1 long and strong; and 1 to 2 short and thin. 

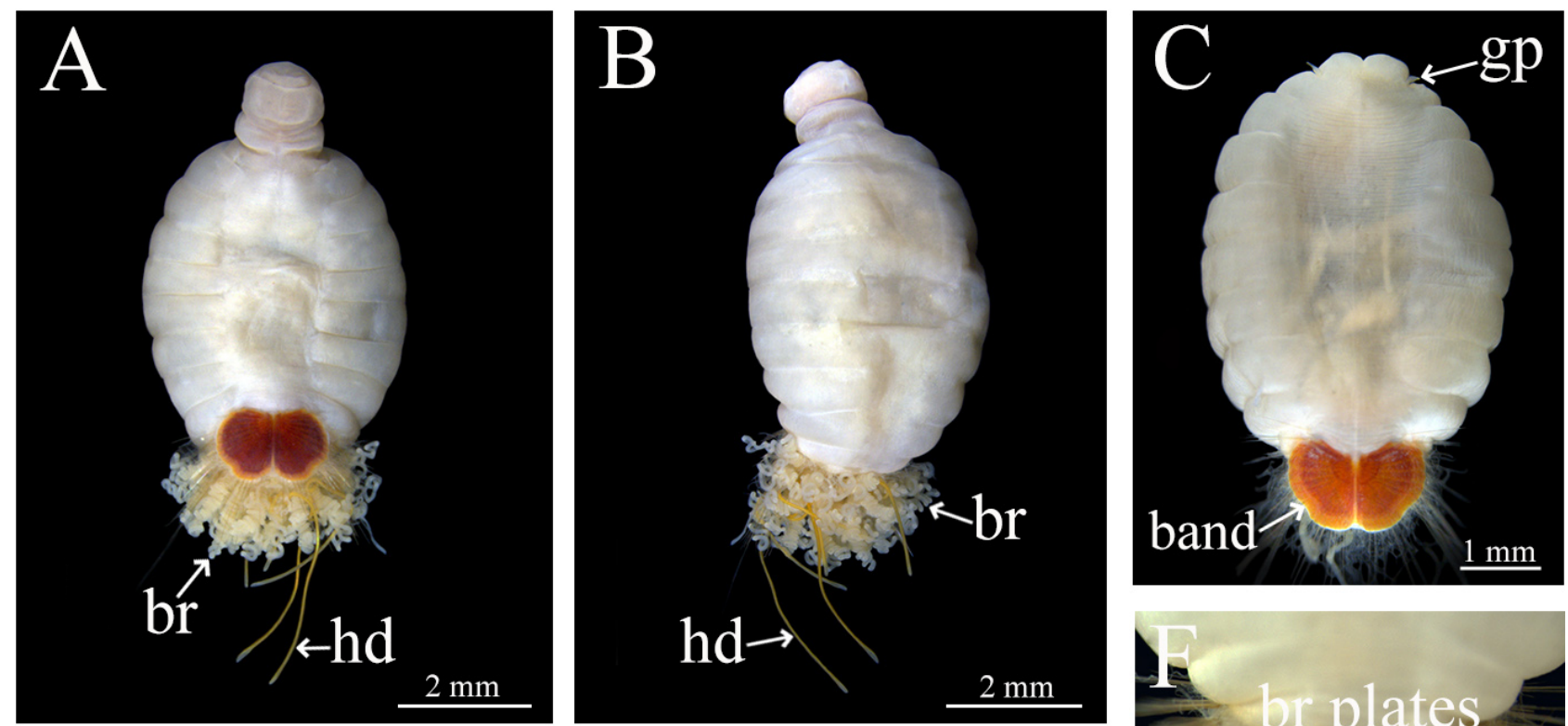

\section{$\mathrm{D}$}
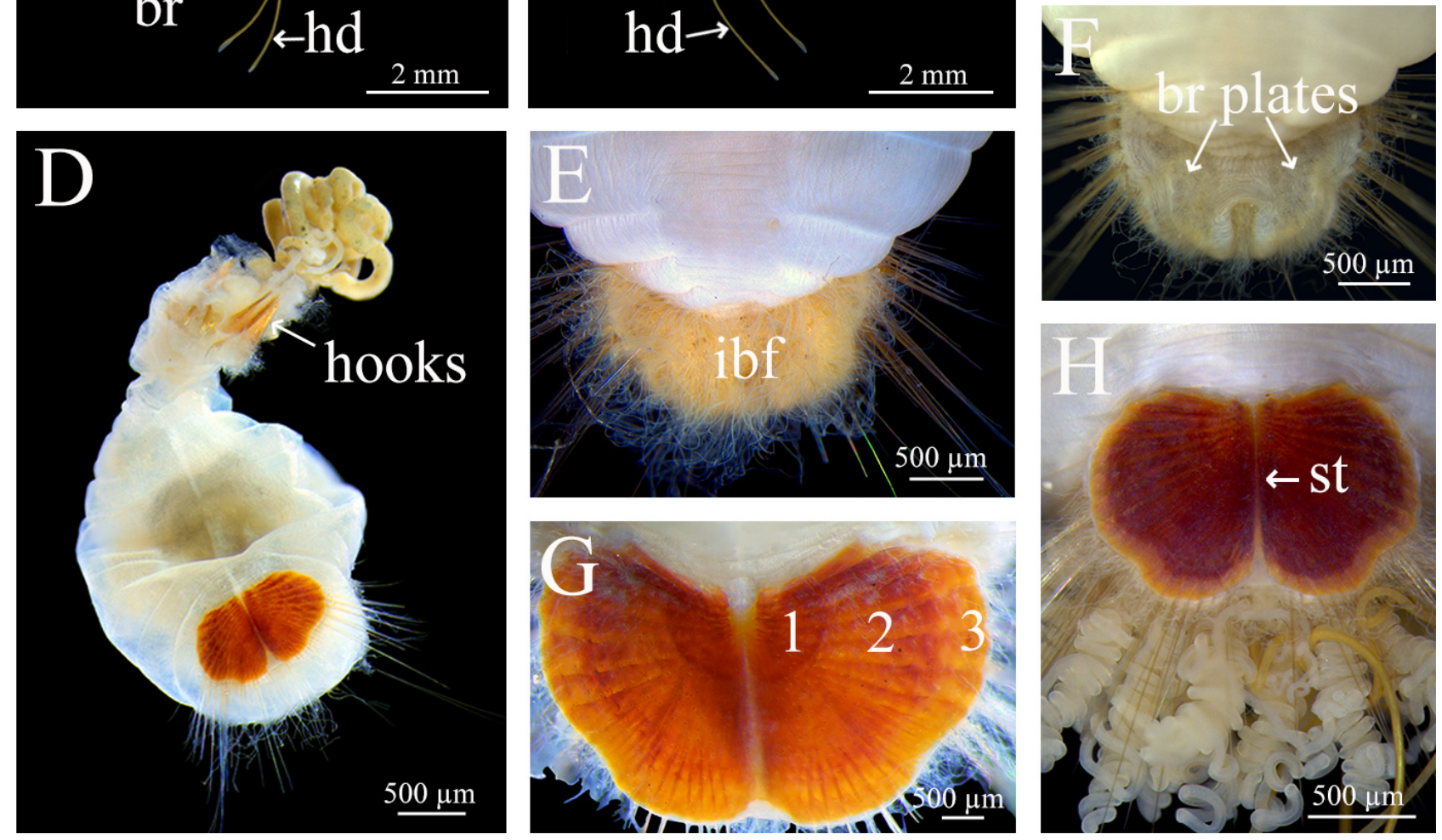

FIGURE 5. Petersenaspis narisarae sp. nov. Light photographs (A-B, H. Holotype, PSUZC-POL-0291; C, G. PSUZC-POL0292; D. PSUZC-POL-0295; E, F. AM W.52925). A. Complete specimen, dorsal view; B. Same, lateral view; C. Complete specimens with introvert invaginated, dorsal view; D. Golden hooks inside the body wall, lateral view; E. Branchial filaments, ventral view; F. Branchial plate after removal of branchiae and longer interbranchial filaments, ventral view; G-H. Ventro-caudal shield, dorsal view. Abbreviations: inner shield 1, medial shield 2, outer shield 3, interbranchial filaments ibf, branchiae br, genital papilla gp, straight filament hd, suture st.

Branchial filaments abundant, comprising two types: coiled, whitish; and straight, brown to golden. Each branchia starts from the branchial plate, the anterior part of the branchia is the base to which the branchia curls back leaving the long filament exposed. Branchiae in paratypes easily detached from branchial plates. Branchial plates wide, parallel distally, divergent basally; interbranchial papillae long, abundant (Fig. 5A, B, E, H).

Variation. Juveniles have shields with barely defined colored bands (Fig. 5D).

Etymology. The species name honors Ms. Narisara Kongcharoenkit, Mr. Sakanan Plathong's secretary, who has helped with coastal and marine resources management for many years.

Habitat. Found at $9 \mathrm{~m}$ depth, in muddy sediments mixed with sand and shells, Gulf of Thailand.

Distribution. Only known from the Songkhla Sea, Gulf of Thailand (Figs 1, 2). 
Remarks. Petersenaspis narisarae sp. nov. belongs to the group of Petersenaspis species that present both a median notch and two lateral notches. It closely resembles $P$. palpallatoci Sendall \& Salazar-Vallejo, 2013, P. apinyae sp. nov., and $P$. pakbaraensis sp. nov. However, $P$. narisarae sp. nov. differs from all these species in having $2-3$ colored bands and an oval abdominal region that is also wider than the abdominal region of other species. These features are unique among all currently described Petersenaspis species. P. narisarae sp. nov., also has a shield that is anteriorly wider than that of $P$. palpallatoci and a lateral shield and genital papillae that are smaller than those of P. palpallatoci.

Furthermore, P. narisarae sp. nov. differs from P. palpallatoci by the color of the introvert hooks, which are golden rather than bright bronze. P. narisarae sp. nov. also has a shield which is anteriorly wider, and a lateral shield that is more strongly curved than P. palpallatoci and exhibits yellow-orange-red bands. In P. palpallatoci, the shield is not anteriorly wider, and the lateral shield is rounded and lacking colored bands. Moreover, $P$. narisarae sp. nov. has 12 fascicles of posterior shield chaetae and 3 capillary chaetae per bundle at the lateral pre-shield rather than 10 fascicles and 2 capillary chaetae per bundle as occurs in P. palpallatoci (Sendall \& Salazar-Vallejo 2013).

Petersenaspis narisarae sp. nov. differs from P. apinyae sp. nov. and P. pakbaraensis sp. nov. in the morphology of the lateral and posterior shields and their margins. In P. narisarae sp. nov. these characters are more rounded, whereas the lateral shield in $P$. apinyae sp. nov. is strongly curved with a very expanded anterior region and the posterior shield is straighter. In P. pakbaraensis sp. nov. the lateral shield is expanded anteriorly, and the posterior shield is expanded laterally. Moreover, $P$. narisarae sp. nov. presents 2 posterior shield chaetae per fascicle, while $P$. apinyae and $P$. pakbaraensis both present 3-4 chaetae per fascicle. The abdominal region in $P$. narisarae sp. nov. is more expanded into an oval shape than in $P$. apinyae sp. nov. and $P$. pakbaraensis sp. nov., which both have a narrower abdomen. The genital papillae in P. narisarae sp. nov. are smaller than they are in $P$. apinyae sp. nov. and P. pakbaraensis sp. nov..

\section{Petersenaspis pakbaraensis sp. nov.}

LSID urn:lsid:zoobank.org:act:3930540A-9BFA-483F-A008-54BB11DDDDFE

Figs 6-7

Material examined. 28 specimens, all collected from Pak Bara, Mu Ko Phetra National Park, in the Andaman Sea, Satun Province, Thailand; muddy sediments mixed with sand; coll. Marine Ecosearch Management Company (MEM) Holotype: PSUZC-POL-0296 (1 spec.), PAK-C3-B1 (651'6.6”N, 9943’36.8”'E), 16 Nov 2019, 1.5 m. Paratypes: PAK-S2 (651'9.3”N, 9943'33.7’'E), 4 Jul 2019; PSUZC-POL-0297 (3 specs., 1 spec. on SEM stub), PAK-S2-B1; PSUZC-POL-0298 (2 specs.); PAK-S3 (651’7.5”N, 9943’33.2”E), 4 Jul 2019; PSUZC-POL-0299 (3 specs.), PAK-S3-B1; PSUZC-POL-0300 (3 specs., 1 spec. on SEM stub), PAK-S3-B3; PSUZC-POL-0301 (1 spec.), PAK-S1-B1 (651’10.8”N, 9943’34”E), 16 Nov 2019; PAK-C1 (651'9.3”N, 9943’38.3”E), 16 Nov 2019; PSUZC-POL-0302 (4 specs., 2 specs. on SEM stubs), PAK-C1-B1; PSUZC-POL-0303 (2 specs.), PAK-C1-B2; PSUZC-POL-0304 (2 specs.), PAK-C2-B1 (651'7.9”N, 9943'37.9”'E), 16 Nov 2019; PSUZC-POL-0305 (2 spec.,

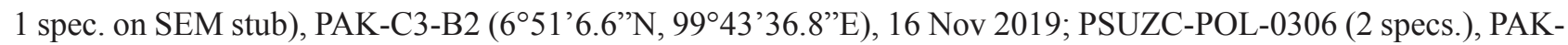

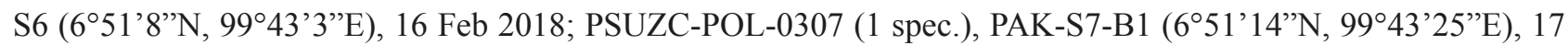
Feb 2018; PSUZC-POL-0308 (1 spec.), PAK-S7-B2 (651'14”N, 9943’25”E), 17 Feb 2018; AM W.52924 (1 spec.), PAK-S2 (651'9.1’N, 9943’36.7’E), 4 Jul 2019.

Description. Holotype complete with sediment particles; body papillose, $7.0 \mathrm{~mm}$ long, $2.9 \mathrm{~mm}$ wide, abdomen $4.6 \mathrm{~mm}$ long (Fig. 6A), grayish to whitish in alcohol; body wall thin, transparent (Fig. 6A, B). Paratypes: eight specimens complete with exposed anterior region, 3.7-8.0 mm long, 2.2-2.6 mm wide, and abdomen 4.3-5.2 mm long; 13 specimens with introvert invaginated; body $3.3-6.2 \mathrm{~mm}$ long, $1.9-4.4 \mathrm{~mm}$ wide. Live specimens showed movement by extending and retracing the anterior part of the body (the prostomium and chaetiger 1-7) to the posterior part or abdomen. When retracted, the prostomium and first three chaetigers were not exposed.

Prostomium rounded, rugose; peristomium surrounds prostomium, including mouth. Mouth circular with small papillae, extending from base of prostomium to anterior edge of first chaetiger (Fig. 7A, D).

First three chaetigers with 8-13 large golden spatulate hooks, and 5-6 smaller thin golden spatulate hooks, without subdistal dark areas; hook numbers similar along chaetigers 1-3. Genital papillae, small, short, thin digitiform, protrude ventrally from body wall between segments 7 and 8 . 

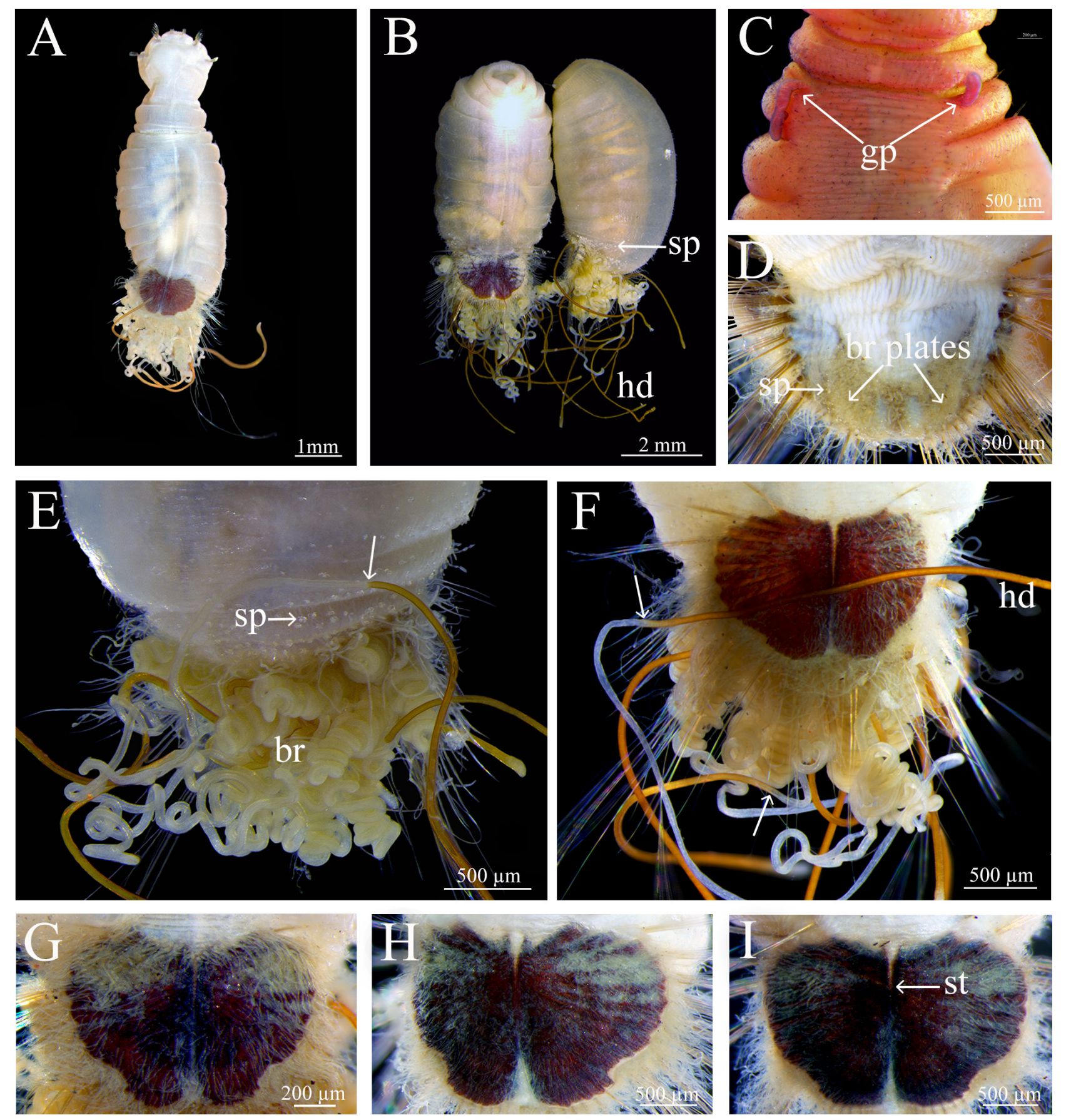

FIGURE 6. Petersenaspis pakbaraensis sp. nov. Light photographs (A, C. Holotype PSUZC-POL-0296; B. PSUZC-POL0297; D. PSUZC-POL-0301; E-F. PSUZC-POL-0299; G. PSUZC-POL-0303; H. PSUZC-POL-0298; I. PSUZC-POL-0305). A. Complete specimen, dorsal view; B. Complete specimens with introvert invaginated, dorsal and lateral view; C. Genital papillae, dorsal view; D. Branchial plate after removal of branchial and interbranchial filaments, ventral view; E. Branchiae, arrow points to the connection area between branchia and filament, ventral view; F. Branchial region and ventro-caudal shield, arrow points to the connection area between branchia and filament, dorsal view; G-I. Ventro-caudal shields, dorsal view. Abbreviations: branchiae br, genital papilla gp, sand particles sp, straight filament hd, suture st.

Pre-shield region with 8 segments, single lateral bundles of 2-3 capillary chaetae protruding from body wall along segments 8-15 (Figs 6A-C, 7A-C, F). Paratypes with capillaries along chaetigers 8-13. Dorsal and ventral body papillae are small, minute, lateral body papillae long and thin.

Ventro-caudal shield heart- or kidney-shaped, dark red to dark purplish, almost black. Surface with abundant long papillae, integument with ciliary clumps and suture extended throughout shield (Figs 6A, B, F-I, 7A). Ribs dis- 
tinct, concentric lines indistinct. Anterior margins angular, anterior depression shallow. Anterior keels not exposed. Lateral margins strongly curved, lobate, expanded anteriorly, reduced posteriorly. Fan with median notch and two lateral notches, posterior notch longer, median notch deep (Fig. 5F, H, I).

Marginal shield chaetal fascicles include 9 lateral fascicles with chaetae, fascicles in oval arrangement, and 12 posterior fascicles, 7 at the posterior and 5 laterals (posterior chaetae mostly in bundles of three).
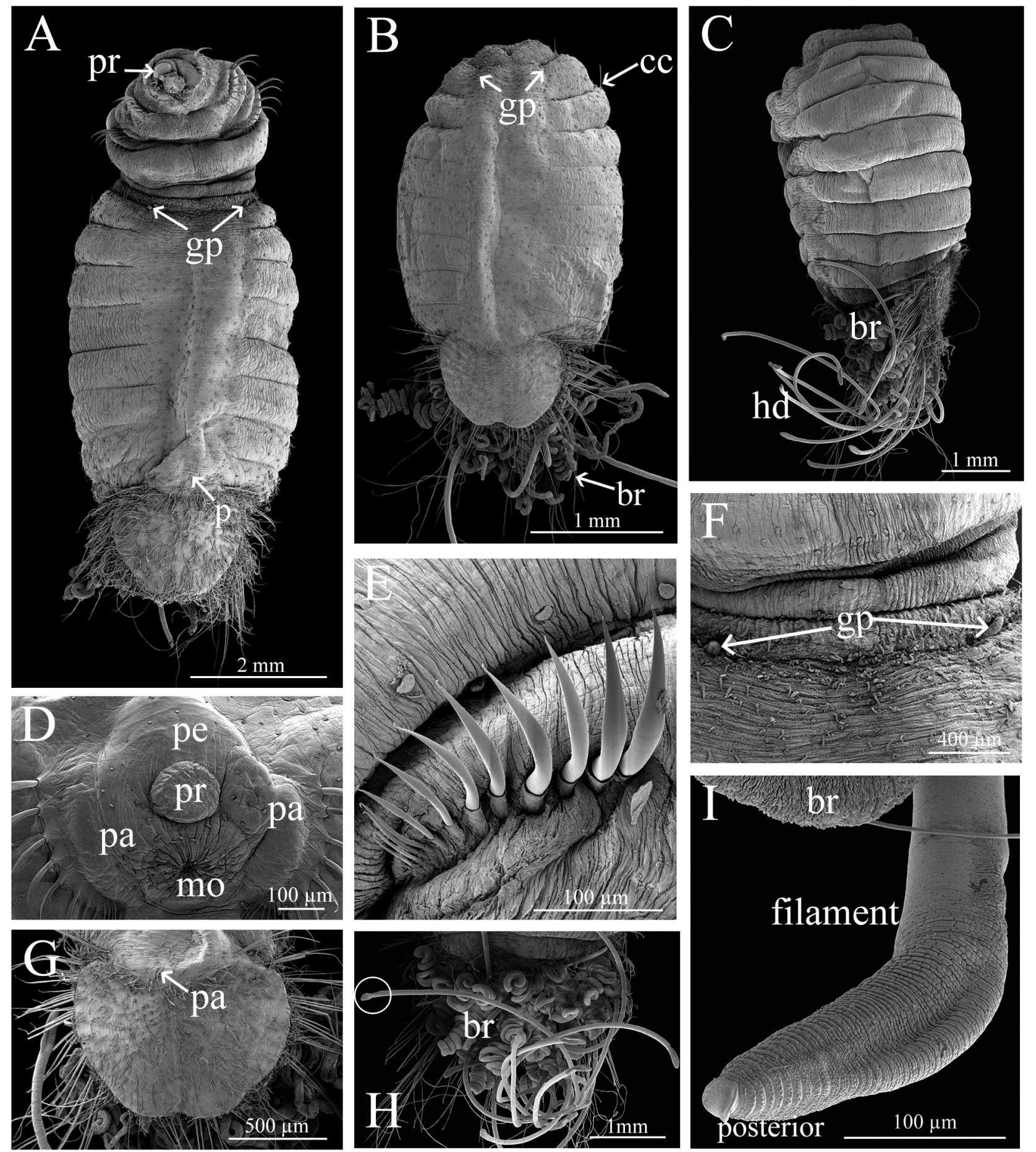

FIGURE 7. Petersenaspis pakbaraensis sp. nov. (A, E-G. PSUZC-POL-0297; B, I. PSUZC-POL-0299; C, H. PSUZC-POL0305; D, G. PSUZC-POL-0302). A. Complete specimen, ventral view; B. Another complete specimen, introvert invaginated, ventral view; C. Same, lateral view; D. Anterior end, frontal view; E. Spatulate neurohooks of chaetiger 1, frontal view; F. Genital papillae, frontal view; G. Ventro-caudal shield, frontal view; H. Branchial region, tip of posterior filament in circle, ventral view; I. Tip of straight filament associated with branchia, lateral view. Abbreviations: branchiae br, capillary chaeta cc, genital papilla gp, straight filament hd, mouth mo, papilla pa, peristomium pe, prostomium pr. 
Branchiae abundant, emerging from a pair of branchial plates, with abundant sediment particles (Figs 6B, D-F, 7B, C, H). Branchial filaments include two types: coiled, whitish filaments and long straight, golden or brownish filaments, filament tips stout and smooth (Figs 6A, B, E, F, 7B, C, H). These two parts are connected by a small ring at the end of the branchial body (whitish) and the base of the filament (brownish); the ring can only be observed by SEM.

Variation. The ventro-caudal shield varies in large and small specimens. In larger specimens, shields are darker purple and the lateral margin of the posterior shield is expanded. In smaller specimens, shields are dark red and the lateral margin of the posterior shield is either not expanded or only slightly expanded. Ciliary clumps and papillae on the shield surface are long and more abundant in larger specimens. Genital papillae are short in paratypes and additional specimens; they are long only in the holotype, which suggests that they are retractable.

Etymology. This species named is after Pak Bara, the locality where the specimens were collected.

Habitat. The intertidal zone at Pak Bara, Mu Ko Phetra National Park, Southern of Thailand.

Distribution. Only known from the type locality, Pak Bara, Andaman Coast, Southern Thailand (Figs 1, 2).

Remarks. Petersenaspis pakbaraensis sp. nov. Resembles P. palpallatoci Sendall \& Salazar-Vallejo, 2013 and $P$. apinyae sp. nov., in having homogenously pigmented shields, and the presence of both a median notch and two lateral notches. However, P. pakbaraensis sp. nov. differs from P. palpallatoci in having a dark purple, almost black, shield with a fan about half as wide as the anterior shield margins whereas $P$. palpallatoci has a reddish shield with a fan about as wide as the anterior margins (Sendall \& Salazar-Vallejo 2013).

Petersenaspis pakbaraensis sp. nov. differs from P. apinyae sp. nov. in having sediment particles on the body surface and branchial plates. Also, the papillae on the shield surface are longer and more abundant, and the integument has ciliary clumps. In P. apinyae sp. nov., the body surface and branchial plates are without sediment particles, the papillae on the shield surface are short and the integument is without ciliary clumps. Moreover, the shield of P. pakbaraensis sp. nov. is dark red to purple, the posterior shield longer and the lateral posterior shield more expanded than in $P$. apinyae sp. nov., which has a deeper reddish shield, the posterior shield margins are wider than they are long and the lateral posterior shield is not expanded.

\section{Discussion}

All three new species of the genera Petersenaspis from Thailand: $P$. apinyae sp. nov., $P$. narisarae sp. nov., and $P$. pakbaraensis sp. nov. have the same type of body branchiae with whitish and brownish filaments at the posterior margins. The long brownish filament is a character that makes this type of branchia unique and this is the first record of this filament observed in a species of Petersenaspis. This filament has not previously been ascribed to another species of Petersenaspis. It is perhaps possible that the filament was present in other observed specimens but broken since it is connected to the branchial plate surface only by a small ring and is easily separated. The filament could have been lost in specimens of other species, leaving only the other, whitish, branchial filaments. Because the tip of this brownish filament is smooth and resembles a sucker, the filament might be help to anchor individuals to the substrate.

The results of intensive long term monitoring and collection of benthic fauna in the Gulf of Thailand, and the Songkhla Sea, suggest that high numbers of $P$. apinyae sp. nov. occur only offshore, but $P$. narisarae sp. nov. was found in shallow waters in Songkhla Province. Likewise, P. pakbaraensis sp. nov. was found only on the intertidal mudflat at Pak Bara, Mu Ko Phetra National Park, Satun Province, on the Andaman Coast. Each species was collected from a different depth and location. They also have differently shaped shields and different colors. The difference between juveniles and adults can be established from the size of specimens, the thickness of the body wall and the thickness of the shield. Juveniles are very small and the body wall and shield are transparent, the shield being light yellow-orange. In smaller juveniles, the body wall is very thin and transparent; the shield light yellow, and as thin and transparent as the body wall. Because of this transparency, even when the introvert is invaginated, the color of hooks is visible. Meanwhile, adults, especially P. apinyae sp. nov. and P. narisarae sp. nov., have opaque, nontransparent body walls, and shields are stiffer and darker. Thus, it was difficult to see eggs inside adults. However, when the abdomen of one paratype of $P$. apinyae was dissected, numerous oocytes were found in the coelom. 


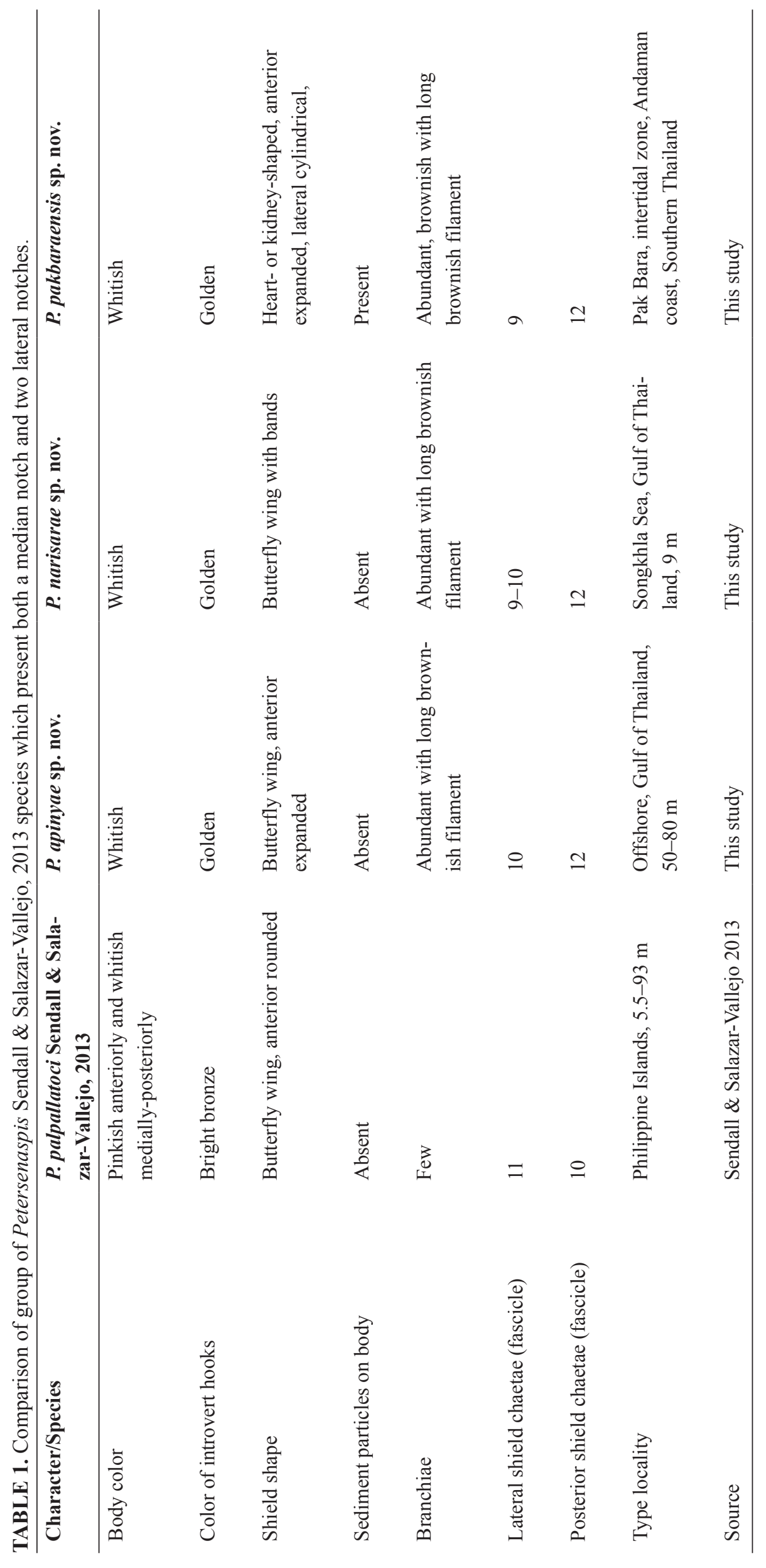




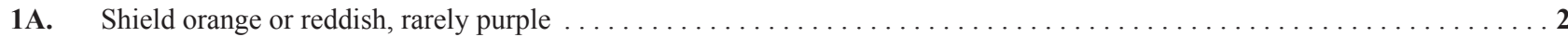

1B. Shield bluish, anterior margin projected forward; anterior segments with four bands of dark brown papillae...........

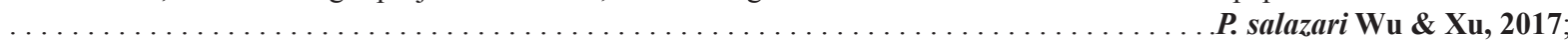

South China Sea

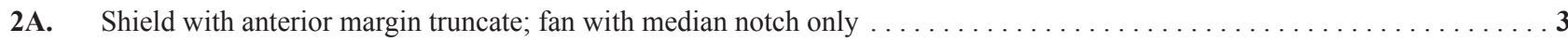

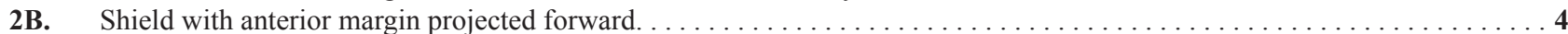

3A. First-three chaetigers with about 10 introvert hooks per side $\ldots \ldots \ldots \ldots \ldots \ldots \ldots \ldots \ldots$. capillata Nonato, 1966;

Central and Southern Brazil

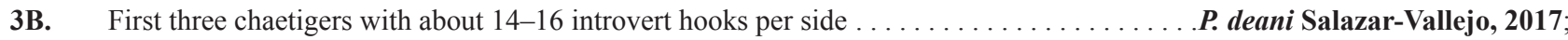
Costa Rica

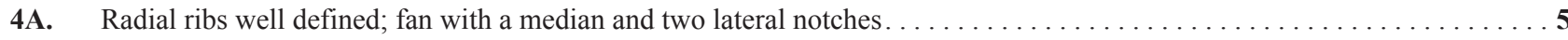

4B. Radial ribs barely defined; fan with median notch, no lateral notches $\ldots \ldots \ldots \ldots \ldots$. harrisae Salazar-Vallejo, 2017; South Africa

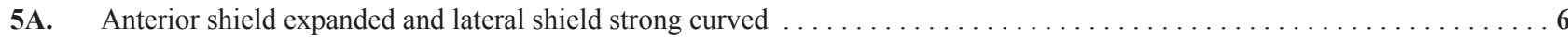

5B. Anterior shield rounded, not expanded and lateral shield rounded . . . . . . P. palpallatoci Sendall \& Salazar-Vallejo, 2013; off Kalibo, Philippines

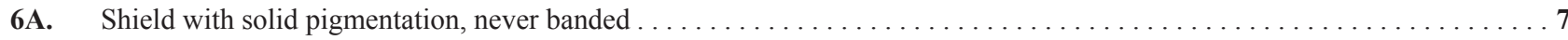

6B. Shield with $2-3$ concentric color bands, without ciliary clumps $\ldots \ldots \ldots \ldots \ldots \ldots \ldots \ldots \ldots \ldots$ narisarae sp. nov.;

Gulf of Thailand, Western Pacific

7A. Shield butterfly wing-shaped, dark reddish without ciliary clumps $\ldots \ldots \ldots \ldots \ldots \ldots \ldots \ldots \ldots$. $\ldots \ldots$ apyae sp. nov.;

Gulf of Thailand, Western Pacific

7B. Shield heart- or kidney-shaped, dark purple with ciliary clumps; posterior margin of fan strongly projected, and laterally expanded. . . . . . . . . . pakbaraensis sp. nov.;

Andaman Coast, Southern Thailand

\section{Acknowledgments}

We would like to thank Mr. Winai Theppulpon, Mr. Weerayut Sripoka, and all the staff of MEM (Marine Ecosearch and Management Co., Ltd.) for their contributions to field and laboratory work. Special thanks go to CEC International (Thailand Branch) Co., Ltd. for project grants to SP, and to the Coral Reef and Benthos Research Unit, Prince of Songkla University (PSU). SEM work was supported by MEM and the Marine Science Learning Center (PSU). The authors would like to thank Ms. Supaporn Prempree, Marine National Park Operation Center, Trang and Mr. Wittaya Boonchit, Mu Ko Phetra National Park for field sampling work. Thanks also to the Chevron (Thailand) Exploration and Production Company for allowing us to collect specimens from their offshore fields. We are grateful to Mr. Monrach Intarasiri, Ms. Siriluk Sutthinun and Mr. Winai Pransuk for photographic assistance, Mr. Rueangrit Promdam and Dr. Prannee Sarrdrit at Princess Maha Chakri Sirindhorn Natural History Museum (Prince of Songkla University) for helping with the collection. Thanks to OSIT, the Office of Scientific Instrument and Testing, PSU for discounted FESEM service and also to Mrs. Apinya Sukolra and Ms. Benjaporn Nooklay for their assistance with SEM. Finally, special thanks to Mr. Thomas Duncan Coyne for proofing and editing the English text of the final draft of our manuscript.

\section{References}

Angsupanich, S. \& Kuwabara, R. (1995) Macrobenthic fauna in Thale Sap Songkla, a brackish lake in southern Thailand. Lakes \& Reservoirs: Research \& Management, 1 (2), 115-125. https://doi.org/10.1111/j.1440-1770.1995.tb00012.x

Fiege, D. (2019) Sternaspidae Carus, 1863 In: Purschke, G., Böggemann, M. \& Westheide, W. (Eds.), Handbook of Zoology. Annelida. Vol. I. Annelida Basal Groups and Pleistoannelida, Sedentaria I. De Gruyter, Berlin, pp. 440-455.

Plathong, J., Hemnukul, P., Sutthinun, S., Ninyong, N., Theppulpon, W., Sawetwes, C., Sangsen, W., Kassen, N., Billee, N., Sripoka, W., Pradoo, S., Jaroenmart, K. \& Plathong, S. (2014) Temporal Variation of Macrobenthic community in the Sea of Songkhla Province. In: Piromvaragorn, S. \& Maiphae, S. (Eds.), Proceedings of the $4^{\text {th }}$ National Marine Science Conference. The $60^{\text {th }}$ Anniversary of His Majesty the King's Accession to the Throne International Convention Center. Prince of Songkla University, 10-12 June 2014, Bangkok, pp. 179-189. [in Thai] 
Read, G. \& Fauchald, K. (Eds.) (2021) World Polychaeta Database. Petersenaspis Sendall \& Salazar-Vallejo, 2013. Accessed through: World Register of Marine Species. Available from: http:/www.marinespecies.org/aphia.php?p=taxdetails\&id=72 4758/ (accessed 19 January 2021)

Rodcharoen, E. (2009) Macrobenthic fauna communities at Ko Nu, Songkhla Province. Master of Science thesis, Prince of Songkhla University, Hat Yai, Songkhla, 85 pp. [in Thai]

Salazar-Vallejo, S.I. (2017) Six new tropical sternaspid species (Annelida, Sternaspidae) with keys to identify genera and species. Zoological Studies, 56 (32), 1-16. https://doi.org/10.6620/ZS.2017.56-32

Sendall, K. \& Salazar-Vallejo, S.I. (2013) Revision of Sternaspis Otto, 1821 (Polychaeta, Sternaspidae). ZooKeys, $286,1-74$. https://doi.org/10.3897/zookeys.286.4438

Tantikamton, K., Thanee, N., Jitpukdee, S. \& Potter, M. (2015) Species diversity and ecological characteristics of benthic macroinvertebrates in the intertidal zone of Satun Province, Thailand and the first record of Petersenaspis sp. International Journal of Advances in Agricultural \& Environmental Engineering, 2 (1), 23-27. https://doi.org/10.15242/IJAAEE.C0415023

Wu, X. \& Xu, K. (2017) Diversity of Sternaspidae (Annelida: Terebellida) in the South China Sea, with descriptions of four new species. Zootaxa, 4244 (3), 403-415.

https://doi.org/10.11646/zootaxa.4244.3.8 